\title{
Endoscopic Submucosal Dissection Skills Transfer to Clinical Practice after Hands-On Workshops: An International Survey
}

\author{
Ricardo Küttner-Magalhães ${ }^{a, b}$ Mário Dinis-Ribeiro ${ }^{c, d}$ Ricardo Marcos-Pinto ${ }^{a, b}$, d \\ Carla Rolanda ${ }^{\mathrm{e}}$, g Arjun D. Koch ${ }^{\mathrm{h}}$ \\ aDepartment of Gastroenterology, Santo António Hospital, Porto University Hospital Center, Porto, Portugal; \\ bInstitute of Biomedical Sciences Abel Salazar, University of Porto, Porto, Portugal; 'Department of Gastroenterology, \\ Portuguese Oncology Institute of Porto, Porto, Portugal; d Department of Community Medicine, Health \\ Information and Decision (MEDCIDS) and CINTESIS, Faculty of Medicine of Porto, Porto, Portugal; ' Department of \\ Gastroenterology, Braga Hospital, Braga, Portugal; ' Life and Health Sciences Research Institute (ICVS), School of \\ Medicine, University of Minho, Braga, Portugal; 9ICVS/3B's, PT Government Associate Laboratory, Braga/Guimarães,

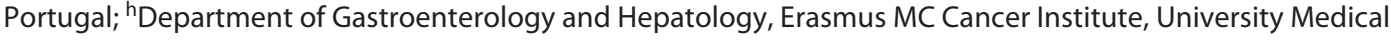 \\ Center, Rotterdam, The Netherlands
}

\section{Keywords}

Endoscopic submucosal dissection - Gastrointestinal endoscopy - Endoscopic skills · Hands-on workshops . Animal models $\cdot$ Simulation $\cdot$ Training

\begin{abstract}
Background: Endoscopic submucosal dissection (ESD) is a complex procedure, requiring enhanced technical skills. Translation into clinical practice of ESD training programs has not been documented. Our aim was to assess ESD training pathways of endoscopists participating in dedicated workshops and its clinical impact on ESD outcomes. Methods: Participants of live porcine models ESD workshops, from 2013 to 2019, were included. They were invited to complete a survey focusing on human ESD performance after training, prior skills/competencies, complete learning pathway, and clinical outcomes. Results: From 118 invited participants, 40 (34\%) completed the questionnaire. Nineteen (47\%) endoscopists performed human ESD after the workshop, predominantly male (89\%). At the beginning of human ESD, endoscopists had a mean of 7.7 (standard deviation
\end{abstract}

(SD) 4.1) years of endoscopic experience and were all performing endoscopic mucosal resection (and emergency endoscopy. Before ESD practice, $100 \%$ of the participants were trained with live animal models and $68 \%$ with ex vivo models. The majority started clinical ESD in the lower third of the stomach or rectum (90\%), with lesions $\leq 30 \mathrm{~mm}(89 \%)$. Each endoscopist performed a median of 19 (interquartile range 8-32) cumulative ESDs, over a mean of 3.9 (SD 2.0) years. Total en bloc resection rate was $92 \%$, R0 resection rate $88 \%$, and curative resection rate $86 \%$, whereas adverse events remained $<10 \%$. Endoscopists with $>10$ human ESD procedures achieve clinical competence thresholds. Conclusions: Participants of ESD workshops are adequately skilled prior to clinical ESD, complying with recommendations for training and properly implementing the technique. Transfer to clinical practice, of prior ESD skills obtained in hands-on training courses, was documented. Structured training programs achieve clinical outcomes exceeding established standards, namely in the very initial clinical phase.

(C) 2021 The Author(s)

Published by S. Karger AG, Basel
Karger@karger.com

www.karger.com/ddi

Karger $\stackrel{\text { ' }}{5}$

BOPEN ACCESS
(C) 2021 The Author(s)

Published by S. Karger AG, Basel

This is an Open Access article licensed under the Creative Commons Attribution-NonCommercial-4.0 International License (CC BY-NC) (http://www.karger.com/Services/OpenAccessLicense), applicable to the online version of the article only. Usage and distribution for commercial purposes requires written permission.
Correspondence to:

Arjun D. Koch, a.d.koch@erasmusmc.nl 


\section{Introduction}

Gastrointestinal cancers represent a clinical heavy burden worldwide. Esophageal, gastric, and colorectal cancers combined represent $18.7 \%$ of total cancer incidence and $22.7 \%$ of cancer-related mortality [1]. Technology development as well as related skills and training present an increasing challenge for diagnosis and treatment of these diseases.

Endoscopic submucosal dissection (ESD) is currently used for treating superficial gastrointestinal neoplasms. The advantages over conventional endoscopic mucosal resection (EMR) are the ability of en bloc, R0 resection of lesions $>20 \mathrm{~mm}$, lowering the risk of local recurrence and allowing reliable histologic evaluation [2, 3]. When compared to surgical treatment in selected patients, ESD is associated with a lower rate of adverse events, shorter operative and hospitalization time, lower costs, and increased quality of live, with similar oncological outcomes $[4,5]$.

However, ESD is a complex procedure, requiring enhanced technical skills, carrying considerable risks of adverse events and has a prolonged learning curve [6]. Hence, ESD training programs [3, 7-11] have been developed. These typically include baseline endoscopic experience, theoretical knowledge, observing/assisting ESD procedures, hands-on training in animal models, and starting clinical practice, under the supervision of an expert. Their widespread implementation has been heterogenous [1214] and clinical benefits have not been demonstrated.

Training in animal models plays an important role in the preclinical early learning phase, leading to an improvement in en bloc resection rates and ESD speed as well as a decrease in adverse events $[15,16]$. Nevertheless, translation into clinical practice of a structured training program has not been yet documented. Our aim was to assess ESD training pathways of endoscopists participating in dedicated workshops and its clinical impact on ESD outcomes.

\section{Methods}

\section{Study Design and Participants}

Participants of EMR and ESD workshops with hands-on training with live porcine models from 2013 to 2019 were invited by email to answer an online survey. The workshops were co-organized by the European Association for Gastroenterology, Endoscopy and Nutrition (EAGEN) as well as the European Society of Gastrointestinal Endoscopy (ESGE) and were supported by a grant from United European Gastroenterology (UEG), to develop the workshop during the first 3 years and make it accessible for endoscopists from all socioeconomic regions in Europe.
The questionnaire was built in Google Forms (Google USA) and sent from July to November 2020 (a maximum of 3 requests, in case of nonresponse). The study protocol was approved by the Institutional Review Board of the Institute of Biomedical Sciences Abel Salazar, University of Porto (Ref No. SD/HCC/79).

Invitees were informed that data would be analyzed and that completing the questionnaire was voluntary. Identity protection and confidentiality of the collected data was guaranteed according to the General Data Protection Regulation. Accordingly and in agreement with the Ethics Committee for Health of the Institute of Biomedical Sciences Abel Salazar, University of Porto, completing the questionnaire implied the participant's implicit acceptance/consent.

\section{Workshops}

Workshops had a duration of 2 days and included theoretical lectures and hands-on practice in live porcine models. They were held in the training centers of the Erasmus School of Endoscopy at the Erasmus University Medical Center in Rotterdam, The Netherlands; Life and Health Sciences Research Institute (ICVS), School of Medicine, University of Minho, Braga, Portugal; and Experimental-Research Center ELPEN, Athens, Greece.

The use of live porcine models for training purposes in the workshop was approved by local Ethical Committees for the welfare of animals in medical training. Procedures were conducted in accordance with the "Animal Research: Reporting of In Vivo Experiments” (ARRIVE) Guidelines [17].

Live pigs (Sus scrofa domesticus) weighing between 30 and 40 $\mathrm{kg}$ were used. Animals were given a liquid diet for 3 days and fasted for $8 \mathrm{~h}$ before the procedures. General anesthesia with endotracheal intubation and mechanical ventilation was performed, according to local protocol, with the support of the veterinarian staff throughout the course.

Fully equipped interventional endoscopy workstations were used under the supervision of international faculty experts. Conventional flexible endoscopes, endoscopic ancillary devices, and electrosurgical units were used. The training modules consisted of esophageal multiband EMR, esophageal ESD, gastric ESD, as well as adverse event management, as previously described [18].

\section{Survey Questionnaire}

The questionnaire was divided into 7 parts. Demographic data were initially collected. Then, the participants were inquired if they were performing human ESD after attending the workshops. If they were nott, reasons for that were assessed. Endoscopists practicing clinical ESD (human ESD in the endoscopist's hospital) were asked to continue the survey. Further domains focused on skills/ competence prior to starting clinical ESD, training methods employed, clinical ESD performance with outcomes (characterized according to the European Guidelines definitions [3]), and appreciation of the learning pathway (in a 10-point Likert scale).

Statistical Analysis

The IBM ${ }^{\circledR}$ Statistical Package for Social Sciences (SPSS ${ }^{\circledR}$, Version 26; SPSS Inc, Chicago, IL, USA) software was used to store and analyze data. Descriptive statistics were determined for all measures according to type of variables. For quantitative variables, means (with SD) were described when data assumed a normal distribution according to the Shapiro-Wilk test, Kolmogorov-Smirnov and visual inspection of histograms, and normal Q-Q plots. Otherwise, medians (with interquartile range (IQR) 25-75) were employed. Paramet- 


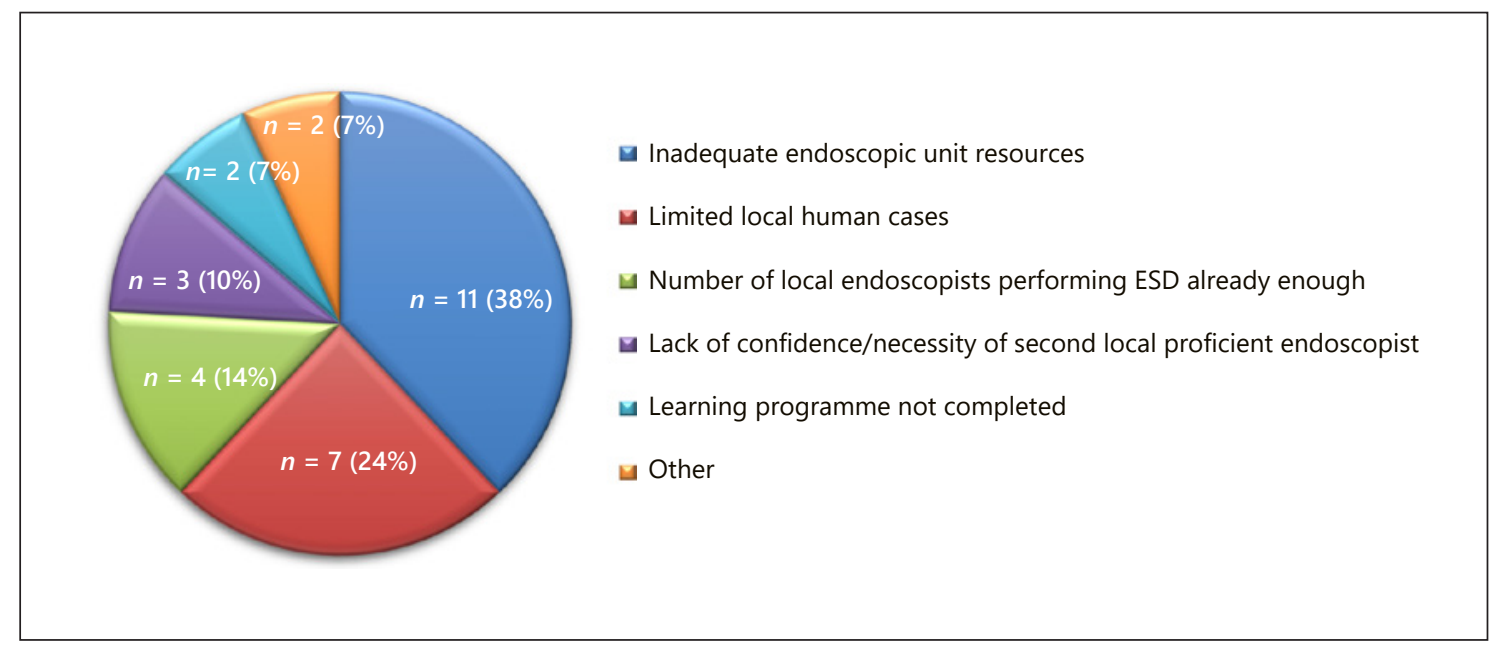

Fig. 1. Reasons for not starting ESD in humans.

Table 1. Participants' characterization

\begin{tabular}{|c|c|c|c|c|}
\hline & Global & $\begin{array}{l}\text { Performing ESD } \\
\text { in humans }\end{array}$ & $\begin{array}{l}\text { Not performing ESD } \\
\text { in humans }\end{array}$ & $p$ value \\
\hline Participants, $n$ (\%) & $40(100)$ & $19(47)$ & $21(53)$ & \\
\hline Female (\%) & $10(25)$ & $2(11)$ & $8(38)$ & 0.044 \\
\hline Age in years, mean (SD) & $43.9(7.7)$ & $43.9(6.9)$ & $44.0(8.7)$ & 0.982 \\
\hline \multicolumn{5}{|l|}{ Origin, $n(\%)$} \\
\hline Europe & $32(80)$ & $14(74)$ & $18(86)$ & \multirow[t]{4}{*}{0.307} \\
\hline Asia & $5(12)$ & $2(10.5)$ & $3(14)$ & \\
\hline South America & $2(5)$ & $2(10.5)$ & 0 & \\
\hline Oceania & $1(3)$ & $1(5)$ & 0 & \\
\hline \multicolumn{5}{|l|}{ Background formation, $n(\%)$} \\
\hline Gastroenterology & $38(95)$ & $18(95)$ & $20(95)$ & \multirow[t]{2}{*}{0.942} \\
\hline Surgery & $2(5)$ & $1(5)$ & $1(5)$ & \\
\hline \multicolumn{5}{|l|}{ Working place, $n(\%)$} \\
\hline Academic or tertiary center & $26(65)$ & $15(79)$ & $11(52)$ & \multirow[t]{3}{*}{0.178} \\
\hline Regional hospital & $13(32)$ & $4(21)$ & $9(43)$ & \\
\hline Private clinic & $1(3)$ & 0 & $1(5)$ & \\
\hline Follow-up after workshop, in years, mean (SD) & $3.5(2.3)$ & $3.9(2.0)$ & $3.2(2.5)$ & 0.318 \\
\hline
\end{tabular}

ric and nonparametric tests were used to assess statistical differences between groups ( $t$ test or Mann-Whitney $U$ test). Proportions were reported for categorical variables and comparisons performed with $\chi^{2}$ test. Significance level was defined as $p<0.05$.

\section{Results}

\section{Participants}

From 118 invited participants, 40 (34\%) completed the questionnaire. The mean global age was 43.9 (standard deviation [SD] 7.7) years, $75 \%$ were male, $95 \%$ gastroen- terologists, $80 \%$ were working in Europe and $65 \%$ in academic or tertiary centers (Table 1). The mean follow-up after the workshop was 3.5 (SD 2.3) years. Nineteen (47\%) endoscopists performed human ESD after the workshop. From these, there was a predominance of male gender $(89 \%)$ as well as working in academic or tertiary centers (79\%). In total, $20 \%(2 / 10)$ of the female participants started clinical ESD, while $56.7 \%$ (17/30) of males did so ( $p=$ $0.047)$. Major reasons not to initiate human ESD were inadequate endoscopic unit resources (38\%) and limited local human cases suitable for the technique (24\%) (Fig. 1). 
Table 2. Skills/competence when starting clinical ESD and training

\begin{tabular}{|c|c|}
\hline & $n=19$ \\
\hline Familiarity with endoscopic classifications, $n(\%)$ & $19(100)$ \\
\hline \multicolumn{2}{|l|}{ Endoscopic experience (after formal residency program) } \\
\hline Years, mean (SD) & $7.7(4.1)$ \\
\hline \multicolumn{2}{|l|}{ Performance of } \\
\hline Upper GI EMR, $n(\%)$ & $19(100)$ \\
\hline Lower GI EMR, $n(\%)$ & $19(100)$ \\
\hline Inject and snare EMR, $n(\%)$ & $19(100)$ \\
\hline Band and snare EMR, $n(\%)$ & $14(74)$ \\
\hline Cap and snare EMR, $n(\%)$ & $12(63)$ \\
\hline Bleeding control (emergency procedures), $n(\%)$ & $19(100)$ \\
\hline $\mathrm{ERCP}, n(\%)$ & $11(58)$ \\
\hline EUS, $n(\%)$ & $9(47)$ \\
\hline \multicolumn{2}{|l|}{ Before starting clinical ESD } \\
\hline "ESD theory literature," $n(\%)$ & $18(95)$ \\
\hline ESD meetings, symposiums, conferences, and live demonstrations, $n(\%)$ & $18(95)$ \\
\hline \multicolumn{2}{|l|}{ After starting clinical ESD } \\
\hline ESD meetings, symposiums, conferences, and live demonstrations, $n$ (\%) & $19(100)$ \\
\hline On site observation of human ESD performed by experts, $n(\%)$ & $18(95)$ \\
\hline How many, median (IQR) & $3(1-4)$ \\
\hline Assistance in human ESD, $n(\%)$ & $9(47)$ \\
\hline How many, median (IQR) & $2(1-3.5)$ \\
\hline Confirmation of knowledge and skills, by an ESD expert, before clinical ESD, $n$ (\%) & $10(53)$ \\
\hline \multicolumn{2}{|l|}{ Before starting clinical ESD } \\
\hline Courses with ex vivo animal models, $n(\%)$ & $13(68)$ \\
\hline How many courses, median (IQR) & $2(1.5-3)$ \\
\hline How many ESD procedures (total), median (IQR) & $10(4.5-20)$ \\
\hline Supervision by trainers, $n(\%)$ & $13(100)$ \\
\hline Courses with live animal models, $n(\%)$ & $19(100)$ \\
\hline How many courses, median (IQR) & $3(1-4)$ \\
\hline How many ESD procedures (total), median (IQR) & $10(5-20)$ \\
\hline Supervision by trainers, $n(\%)$ & $19(100)$ \\
\hline \multicolumn{2}{|l|}{ After starting clinical ESD } \\
\hline Courses with ex vivo animal models, $n(\%)$ & $6(35)$ \\
\hline How many, median (IQR) & $2(1-4)$ \\
\hline Courses with live animal models, $n(\%)$ & $9(60)$ \\
\hline How many, median (IQR) & $1(1-2.5)$ \\
\hline Time from first animal model course to first human ESD, months, median (IQR) & $18(6-36)$ \\
\hline Time from last animal model course to first human ESD, months, median (IQR) & $3(1-6)$ \\
\hline
\end{tabular}

ERCP, endoscopic retrograde cholangiopancreatography; EUS, endoscopic ultrasonography.

\section{Skills/Competence when Starting Clinical ESD}

\section{Practice}

At the beginning of human ESD practice, endoscopists had a mean of 7.7 (SD 4.1) years of endoscopic experience (after formal residency program; Table 2). All the participants were familiar with and made use of morphologic and chromendoscopic classifications. They were all performing upper and lower GI EMR and endoscopic bleeding control procedures.

\section{Training}

Before starting human ESD, 95\% had accessed "ESD theory literature" resources (books, articles, DVDs, internet, and including videos) and had attended meetings, symposiums, conferences, and live demonstrations (Table 2). Likewise, 95\% had observed, on site, human ESD procedures performed by experts (median of 3 [IQR 1-4]) and $47 \%$ had assisted in human ESD procedures by manipulation of endoscopic accessories, patient monitoring, drug administration, etc. (median of 2 [IQR 1-3.5]). Confirmation of knowledge and skills 


\begin{tabular}{ll}
\hline & $n=19$ \\
\hline ESD registration in prospective database, $n(\%)$ & $11(58)$ \\
Possibility of admitting patients to a ward, $n(\%)$ & $19(100)$ \\
Access to emergency surgical team, $n(\%)$ & $19(100)$ \\
Access to expert gastrointestinal pathology, $n$ (\%) & $19(100)$ \\
Supervision of an ESD-proficient endoscopist in first human ESD & $10(53)$ \\
How many, $n$ (\%) & \\
$1-5$ & $7(70)$ \\
$6-10$ & $2(20)$ \\
$11-20$ & $1(10)$ \\
Organ of first human ESD, $n$ (\%) & $1(5)$ \\
Esophagus & $1(5)$ \\
Middle third of the stomach & $9(48)$ \\
Lower third of the stomach & $8(42)$ \\
Rectum & \\
Lesion size of first human ESD, $n(\%)$ & $5(26)$ \\
$<20$ mm & $12(63)$ \\
$20-30$ mm & $2(11)$ \\
\hline 30 mm & \\
\hline
\end{tabular}

Table 4. Clinical ESD outcomes

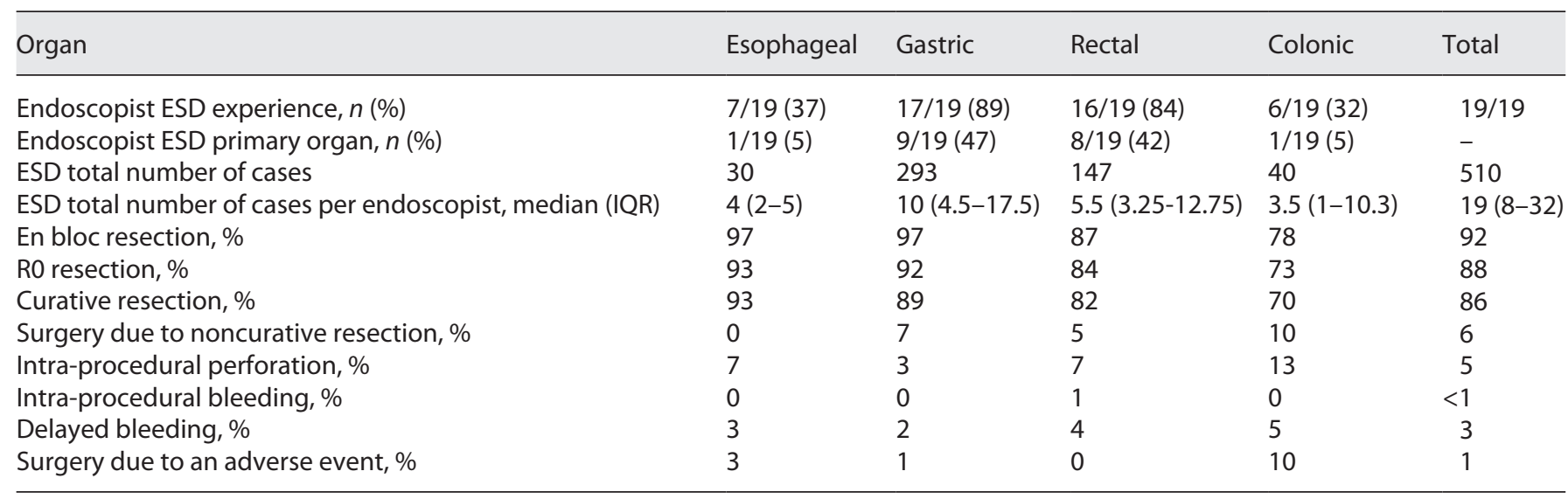

by an ESD expert, before starting clinical ESD was possible in $53 \%$.

Prior to clinical ESD, $68 \%$ trained with supervised ex vivo animal models, attending a median of 2 (IQR 1.5-3) courses and performing a median of 10 (IQR 4.5-20) ESD procedures in total. Regarding supervised live animal models, attendance of courses was $100 \%$, with a median of 3 (IQR 1-4) courses and 10 (IQR 5-20) ESD procedures in total.

After beginning clinical ESD, 35\% continued training with ex vivo animal models, attending a median of 2 (IQR 1-4) courses. Training with live animal models occurred in $60 \%$, with a median of 1 (IQR $1-2.5$ ) course.

Time from first and last animal model course to first human ESD was 18 months (IQR 6-36) and 3 months (IQR 1-6), respectively.

\section{Initial Clinical ESD}

Clinical ESD procedures were prospectively registered by $58 \%$ of participants (Table 3 ). All had access to multidisciplinary management of patients.

The first human ESD was performed under the supervision of a proficient endoscopist in 53\% and was conducted in the lower third of the stomach or rectum in $90 \%$ of cases. The correspondent lesion size was $\leq 30 \mathrm{~mm}$ in $89 \%$.

\section{Clinical ESD Outcomes}

More than $80 \%$ of participants had experience in gastric or rectal ESD ( $89 \%$ and $84 \%$, respectively), and these were the primary organs for which the technique was used ( $47 \%$ and $42 \%$, respectively; Table 4 ). 
Table 5. Outcomes according to the total number of procedures per endoscopist

\begin{tabular}{|c|c|c|c|c|}
\hline Endoscopists, $n$ & 6 & 13 & & 19 \\
\hline ESD total number of cases & 32 & 478 & & 510 \\
\hline ESD total number of cases per endoscopist, median (IQR) & $4.5(3.25-8.50)$ & $30.0(17.0-41.0)$ & 0.001 & $19(8-32)$ \\
\hline ESD number of cases per endoscopist/last year, median (IQR) & $4.0(3.75-4.25)$ & $15.0(10.0-27.0)$ & 0.001 & $10(4-24)$ \\
\hline En bloc resection, \% & 84 & 93 & 0.0799 & 92 \\
\hline $\mathrm{R} 0$ resection, $\%$ & 81 & 89 & 0.2089 & 88 \\
\hline Surgery due to noncurative resection, $\%$ & 15.6 & 5 & 0.0154 & 6 \\
\hline Intra-procedural perforation, $\%$ & 6.3 & 5 & 0.7876 & 5 \\
\hline Intra-procedural bleeding, \% & 0 & $<1$ & 0.8003 & $<1$ \\
\hline Delayed bleeding, \% & 0 & 3 & 0.297 & 3 \\
\hline Surgery due to an adverse event, $\%$ & 0 & 2 & 0.4858 & 1 \\
\hline
\end{tabular}

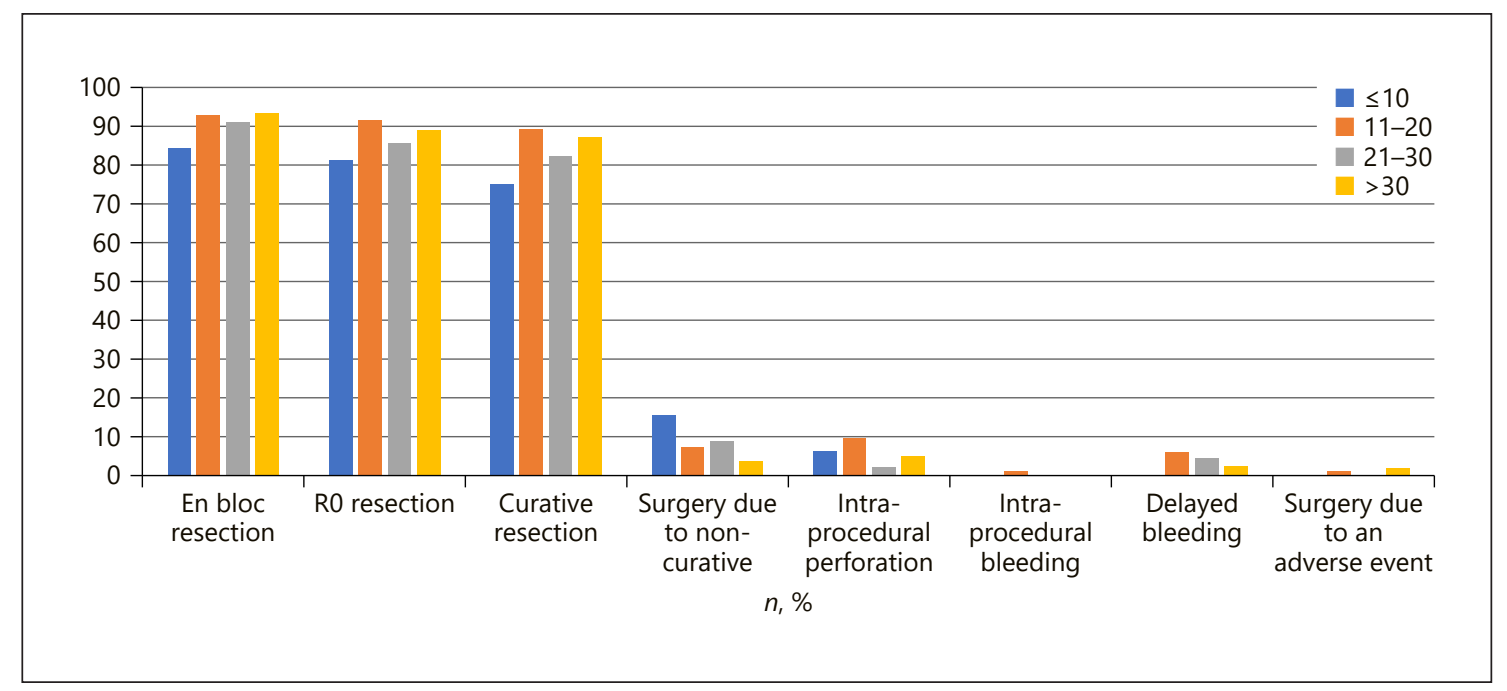

Fig. 2. Outcomes according to the total number of procedures per endoscopist.

Each endoscopist performed a median of 19 (IQR 8-32) cumulative ESDs and a median of 10 (IQR 4-24) ESDs in the last year. Total en bloc resection rate was $92 \%$, R0 resection rate $88 \%$, and curative resection rate $86 \%$, whereas adverse events remained $<10 \%$.

A higher number of gastric ESDs were performed (293 in total; median of 10 (IQR 4.5-17.5) per endoscopist) followed by rectal ESDs (147 in total; median of 5.5 (3.2512.75) per endoscopist).

En bloc resection rates were higher for esophageal (97\%) and gastric (97\%) lesions and lower for rectal (87\%) and colonic lesions (78\%). Similarly, R0 resection rates were higher for esophageal and gastric lesions (93\% and 92\%, respectively) and lower for rectal (84\%) and colonic lesions (73\%). Also, the curative resection rates were higher for esophageal and gastric lesions $(93 \%, 89 \%$, respectively) and lower for rectal (82\%) and colonic lesions (70\%).

Regarding adverse events, globally, intra-procedural perforation and bleeding occurred in $5 \%$ and $<1 \%$, respectively. Delayed bleeding was reported in $3 \%$ and surgery due to an adverse event in $1 \%$. These events were more frequent in the colon with $13 \%$ of intra-procedural perforation and $10 \%$ for surgery due to an adverse event compared to $3 \%$ and $1 \%$, respectively, in gastric procedures.

Endoscopists performing $\leq 10$ human achieved en bloc, R0, and curative resection rates of $84 \%, 81 \%$, and $75 \%$, compared to $93 \%, 89 \%, 87 \%$, respectively, for endoscopists with $>10$ procedures (Table 5). Differences were not statistically significant with the exception of surgery due to noncurative resection ( $15.6 \%$ vs. $5 \%, p=0.0154)$. 
Table 6. Appreciation of the learning pathway

\begin{tabular}{ll}
\hline & $n=19$ \\
\hline Satisfaction with training pathway, median (IQR) & $7(7-9)$ \\
As an ESD trainee, before clinical ESD practice & \\
$\quad \begin{array}{l}\text { Courses with ex vivo animal models } \\
\text { Usefulness, median (IQR) }\end{array}$ & $7(5-10)$ \\
$\quad$ Consideration as a prerequisite, $n(\%)$ & $12(63)$ \\
$\quad$ Courses with live animal models & \\
$\quad$ Usefulness, median (IQR) & $10(9-10)$ \\
$\quad$ Consideration as a prerequisite, $n(\%)$ & $17(89)$ \\
Most valuable individual learning methods & \\
Courses with live animal models & $18(32)$ \\
Human ESD under supervision & $12(21)$ \\
Observing human ESDs performed by experts & $11(19)$ \\
ESD meetings, symposiums, conferences, and live demonstrations & $7(12)$ \\
Courses with ex vivo animal models & $5(9)$ \\
"ESD theory literature" & $4(7)$ \\
Methods lacking for better ESD training & \\
Centers for observing/assisting human ESDs performed by experts & $15(39)$ \\
ESD courses with live animals models & $13(34)$ \\
ESD meetings, symposiums, conferences, or live demonstrations & $4(11)$ \\
ESD courses with ex vivo animal models & $3(8)$ \\
"ESD theory literature" & $3(8)$
\end{tabular}

En bloc, R0, and curative resection rates were above $90 \%, 85 \%$, and $80 \%$, respectively, for endoscopists performing 11-20, 21-30, and >30 (Fig. 2).

\section{Appreciation of the Learning Pathway}

When evaluating the satisfaction with the training pathway of each endoscopist, a median grade of 7 out of 10 (IQR 7-9) was scored (Table 6). The usefulness of courses with ex vivo animal models was appreciated with a grade of 7 (IQR 5-10) and in 63\% they were considered to be a prerequisite prior to human ESD. The usefulness of courses with live animal models was rated with a grade of 10 (IQR 9-10) and they were considered to be a prerequisite by $89 \%$.

Courses with live animal models (32\%), human ESD under direct supervision (21\%) and observing human ESDs performed by experts (19\%) were the most valued learning methods. Endoscopists elected centers for observing/assisting human ESDs performed by experts (39\%) and additional ESD courses with live animal models (34\%) as the main methods lacking for better ESD training.

\section{Discussion}

To the best of our knowledge, this is the first study to describe the transfer to clinical practice, of prior ESD skills obtained in hands-on training courses. Furthermore, structured training programs achieve clinical out- comes exceeding established standards, namely, in the very initial clinical phase.

Endoscopists participating in EMR/ESD workshops are adequately skilled prior to human ESD initiation, complying with most of the pre- and post-clinical steps recommended for training and appropriately implementing the technique in clinical practice. Slightly more than half of the included endoscopists (53\%) did not start human ESD after attendance of the workshops. We might infer that their training plan was not adequately organized and perhaps not every step of the program was timely arranged. Nevertheless, the majority of the invoked reasons can be locally addressed like adjusting endoscopic unit resources and increasing detection/referral of patients with lesions suitable for ESD.

From the endoscopists that started clinical ESD, most were male endoscopists, as in other reports [12]. Familiarity with endoscopic classifications, prior endoscopic therapeutic skills as well as literature and meetings resources were undertaken, in accordance with main recommendations $[3,9,19,20]$. We should take into account that, for instance, the recommendations for ESD training by the ESGE [9] were only issued in 2019 and that many endoscopists had already started clinical ESD by that time.

We noted a current trend to decreasing the endoscopic experience when starting ESD compared to previous Western ESD reports (mean of 7.7 years in the current study vs. median of 15 years in an international survey [14]). However, for ESD learning endoscopists, this expe- 
rience is still not as low as in Japan where, in 1 study, a mean of 5 years of postgraduation was reported [8] and in Korea where $66 \%$ were second year fellows or have finished the fellowship $<5$ years [21].

Animal models are considered an important tool in ESD training $[18,22]$, and the ESGE recommends performing at least 20 procedures before human practice [9]. Accordingly, in our study, a median of 5 courses and 20 procedures were accomplished before clinical ESD. Of note, courses were always supervised as recommended [9]. In the Western setting, these models are a frequently used resource, as manifested in an Italian survey, in which $93 \%$ of endoscopists performing ESD trained with ex vivo and $76 \%$ with live animal models [12]. On the other hand, in Korea, only $60 \%$ of the endoscopists used animal training [21].

In our study, even after starting human ESD, 60\% still used live animal model training. This allows endoscopists with limited initial human cases to maintain continuous exposure to ESD practice, as previously demonstrated [23] and advocated by the ESGE [9]. Such a strategy underlines the importance of assuring additional and ongoing ESD hands-on courses.

Observation/assistance of experts performing ESD and performing the first human procedures with such supervision is usually suggested [3,9-11]. One of the difficulties in implementing ESD in the West is having local available endoscopists. Nevertheless, in this study, 95\% had the opportunity to observe experts and nearly half assisted in human ESD procedures. Also, 53\% were able to start human ESD under supervision, in contrast to only $35.5 \%$ in an Italian survey [12], but still not universally as in Asian countries $[6,8,19-21]$. As recommended, the first procedures were performed in the lower third of the stomach or rectum in approximately $90 \%$ of the cases and none in the colon $[3,9,19,20]$.

The higher number of procedures performed in the stomach and rectum reflect the prevalence of neoplastic lesions in each endoscopist's country but also the intention to work in the safest and most recommended locations in the beginning of the human learning curve.

The number of ESDs performed in the last year (median of 10) is below 25 per year as suggested by the ESGE [9]. This may be explained by the follow-up inferior to 1 year for some endoscopists and because ESD implementation is a progressive, stepwise process. Accordingly, if we consider only endoscopists who performed more than 30 procedures, the median ESD procedures in the last year increase to 24 .

Global clinical outcomes in our study, with resection rates of en bloc $92 \%$, R0 $88 \%$, and curative $86 \%$, achieved the required thresholds advocated by the ESGE [9] (en bloc $>90 \%$, R0 $>80-85 \%$, and curative resections $>75 \%$ ). En bloc, R0, and curative resections rates were higher for esophageal (97\%, 93\%, and 93\%, respectively) and gastric lesions ( $97 \%, 92 \%$, and $89 \%$, respectively), intermediate for rectal lesions $(87 \%, 84 \%$, and $82 \%$, respectively), and lower for colonic lesions $(78 \%, 73 \%$, and $70 \%$, respectively). Combined colorectal ESD, attained an en bloc resection rate of $85 \%, \mathrm{R} 0$ of $82 \%$, and curative of $79 \%$. These results are comparable to or better than other Western series $[12,13,24]$. Adverse events were kept under the $10 \%$ considered for early competence [10] and below other national reports (29-14\%) [13]. The global perforation rate of $5 \%$ in our study, although lower than the $18-8 \%$ [13] or $6 \%$ [12] of other surveys, was superior to the $3 \%$ suggested by the ESGE [9], mainly due to colonic ESD.

Beginning ESD training in humans is strongly discouraged $[3,9,19,20]$. In a study with nonexperienced endoscopists without supervision, the perforation rate was $34 \%$ and the en bloc resection rate $52 \%$ in the initial human rectal ESD practice (first 25 cases) [25]. In our report, despite of a low median number of rectal ESD procedures per endoscopist of 5.5, the perforation rate was $7 \%$ and en bloc resection rate $87 \%$.

En bloc, R0, and curative resection rates $(84 \%, 81 \%$, and $75 \%$, respectively) for endoscopists performing $\leq 10$ human ESDs were below, or at the ESGE-defined competency thresholds [9]. Even so, these outcomes exceed the en bloc resection defined for the early competency $(>80 \%)$ [10], but of course it is not possible to exclude that the initial procedures were less complex. When we address endoscopists with $>10$ procedures the en bloc, $\mathrm{R} 0$, and curative resection rates of $93 \%, 89 \%, 87 \%$, respectively, surpass the established clinical standards [9] and the results of other Western series $[12,13,24]$. Even acknowledging the limitation of number thresholds in endoscopic learning curves [26], assessment of colonoscopy competency is only recommended after 200-300 cases, which represent the average number of procedures to achieve a cecal intubation rate of 90\% [27-29]. As a trainee should not be allowed to practice colonoscopy independently before reaching that threshold (besides other criteria), likewise an ESD trainee should have expert supervision at least in the first 10 human procedures, which is in line with the ESGE recommendations [9].

Therefore, applying a structured training program, including animal model simulation, allows an effective and safe initial human learning curve. Major benefits seem to occur in the early clinical practice, as with validated virtual reality simulators for flexible endoscopy [30, 31]. Other sources of evidence that support the relevance of training, such as prospective comparative studies with or 
without animal model, do not seem appropriate, lacking common sense and ethical reasoning.

In a Korean survey, only $43 \%$ of the participants were satisfied with their training program [21], whereas a median of 7 out 10 was the score attributed in our study. Although the preferred ESD learning methods are common, a greater focus is placed on ESD under supervision/ESD observation in the Asian study [21], while in ours, an emphasis was given to training with animal models. On the other hand, endoscopists in our study look for places in which they can observe/assist ESDs that are scarce in Europe due to the limited number of ESD expertise. In this learning pathway, a clear challenge arises regarding narrowing the existing gap between Asian endoscopist's preferences and European endoscopist's desires (which is the opportunity to observe/assist experts performing human ESD and to start human ESD under supervision) and the European ability to provide such training.

Regarding the strengths of this study, we highlight the worldwide origin of the participants which broadens the impact of our results. Additionally, data are related to a continuum period, addressing different modalities of training, the implementation of the technique, and then the initial human learning curve (where the impact of training program may have a greater impact).

Concerning the limitations, we acknowledge the modest number of respondents (but still satisfactory for this type of study), the low number of procedures performed, and the reliance on self-reported data. In the near future, availability of centers for observation/assisting and starting clinical ESD under expert supervision must be addressed as they are considered scarce, relevant, and desired training methods.

In conclusion, participants of ESD workshops are adequately skilled prior to clinical ESD, complying with recommendations for training and properly implementing the technique. Structured training programs achieve clinical outcomes exceeding established standards, namely, in the very initial clinical phase.

\section{Acknowledgments}

We would like to thank all respondents for completing the survey.

\section{Statement of Ethics}

The use of the live porcine model for training purposes in the workshops was approved by local ethical committees for the welfare of animals in medical training. Procedures were conducted in accordance with the "Animal Research: Reporting of In Vivo Ex- periments" (ARRIVE) Guidelines. The study protocol was approved by the Institutional Review Board of the Institute of Biomedical Sciences Abel Salazar, University of Porto (Ref No. SD/ HCC/79). This was not a research conducted on humans (but based on online questionnaires answered by humans). Only the ones who wished to do so responded willingly and all had the possibility of not doing it if they wished. Invitees were informed that data would be analyzed and that completing the questionnaire was voluntary. Identity protection and confidentiality of the collected data was guaranteed according to the General Data Protection Regulation. Accordingly and in agreement with the Ethics Committee for Health of the Institute of Biomedical Sciences Abel Salazar, University of Porto, completing the questionnaire implied the participant's implicit acceptance/consent. Therefore, the requirement for written informed consent was waived.

\section{Conflict of Interest Statement}

Ricardo Küttner-Magalhães, Ricardo Marcos-Pinto, and Carla Rolanda have no conflicts of interest or financial ties to disclose; Mário Dinis-Ribeiro reports research grants from Olympus and Fujifilm and Medtronic consultancy; and Arjun D. Koch reports speaker fees from Cook Medical, ERBE, Pentax, and Boston Scientific.

\section{Funding Sources}

This research did not receive any specific grant from funding agencies in the public, commercial or nonprofit sectors. The workshops were unrestrictedly sponsored by Pentax ${ }^{\circledR}$ (Tokyo, Japan), ERBE $^{\circledR}$ (Tübingen, Germany), Karl Storz (Tuttlingen, Germany) and, Cook Medical ${ }^{\circledR}$ (Winston-Salem, NC, USA), which provided flexible endoscopes, electrosurgical units, and endoscopic devices. The sponsors had no influence on the scientific content of the workshop neither on this study.

\section{Author Contributions}

All authors have contributed and agreed on the content of the manuscript. Ricardo Küttner-Magalhães contributed to the study conception, study design, data acquisition, data analysis, data interpretation, manuscript writing, and critical revision. Mário DinisRibeiro contributed to the study conception, study design, study supervision, data analysis, data interpretation, and critical revision of the manuscript. Ricardo Marcos-Pinto and Carla Rolanda contributed to the study conception and design, data interpretation, and critical revision of the manuscript. Arjun D. Koch contributed to the study conception and design, study supervision, data analysis, data interpretation, and critical revision of the manuscript. All authors read and approved the final version of the manuscript.

\section{Data Availability Statement}

All data generated or analyzed during this study are included in this article. Further inquiries can be directed to the corresponding author. 


\section{References}

1 Bray F, Ferlay J, Soerjomataram I, Siegel RL, Torre LA, Jemal A. Global cancer statistics 2018: GLOBOCAN estimates of incidence and mortality worldwide for 36 cancers in 185 countries. CA Cancer J Clin. 2018;68(6):394424.

2 Cao Y, Liao C, Tan A, Gao Y, Mo Z, Gao F. Meta-analysis of endoscopic submucosal dissection versus endoscopic mucosal resection for tumors of the gastrointestinal tract. Endoscopy. 2009;41(9):751-7.

3 Pimentel-Nunes P, Dinis-Ribeiro M, Ponchon T, Repici A, Vieth M, De Ceglie A, et al. Endoscopic submucosal dissection: European Society of Gastrointestinal Endoscopy (ESGE) Guideline. Endoscopy. 2015;47(9): 829-54.

4 Liu Q, Ding L, Qiu X, Meng F. Updated evaluation of endoscopic submucosal dissection versus surgery for early gastric cancer: a systematic review and meta-analysis. Int J Surg. 2020;73:28-41

5 Libânio D, Braga V, Ferraz S, Castro R, Lage J, Pita I, et al. Prospective comparative study of endoscopic submucosal dissection and gastrectomy for early neoplastic lesions including patients' perspectives. Endoscopy. 2019; 51(1):30-9.

6 Oda I, Odagaki T, Suzuki H, Nonaka S, Yoshinaga $S$. Learning curve for endoscopic submucosal dissection of early gastric cancer based on trainee experience. Dig Endosc. 2012;24(Suppl 1):129-32.

7 Yamamoto S, Uedo N, Ishihara R, Kajimoto N, Ogiyama H, Fukushima Y, et al. Endoscopic submucosal dissection for early gastric cancer performed by supervised residents: assessment of feasibility and learning curve. Endoscopy. 2009;41(11):923-8.

8 Tsuji Y, Ohata K, Sekiguchi M, Ito T, Chiba $\mathrm{H}$, Gunji T, et al. An effective training system for endoscopic submucosal dissection of gastric neoplasm. Endoscopy. 2011;43(12): 1033-8.

9 Pimentel-Nunes P, Pioche M, Albéniz E, Berr F, Deprez P, Ebigbo A, et al. Curriculum for endoscopic submucosal dissection training in Europe: European Society of Gastrointestinal Endoscopy (ESGE) Position Statement. Endoscopy. 2019;51(10):980-92.

10 Oyama T, Yahagi N, Ponchon T, Kiesslich T, Berr F. How to establish endoscopic submucosal dissection in Western countries. World J Gastroenterol. 2015;21(40):11209-20.

11 Friedel D, Stavropoulos SN. Introduction of endoscopic submucosal dissection in the
West. World J Gastrointest Endosc. 2018; 10(10):225-38

12 Maselli R, Iacopini F, Azzolini F, Petruzziello L, Manno M, De Luca L, et al. Endoscopic submucosal dissection: Italian national survey on current practices, training and outcomes. Dig Liver Dis. 2020;52(1):64-71.

13 Barret M, Lepilliez V, Coumaros D, Chaussade $\mathrm{S}$, Leblanc S, Ponchon T, et al. The expansion of endoscopic submucosal dissection in France: a prospective nationwide survey. United European Gastroenterol J. 2017;5(1): 45-53.

14 Küttner-Magalhães R, Pimentel-Nunes $\mathrm{P}$, Araújo-Martins M, Libânio D, Borges-Canha M, Marcos-Pinto R, Koch AD, et al. Endoscopic submucosal dissection (ESD): how do Western endoscopists value animal models? Scand J Gastroenterol. 2021;56:1-5.

15 Chapelle N, Musquer N, Métivier-Cesbron E, Luet D, Volteau C, Le Rhun M, et al. Efficacy of a three-day training course in endoscopic submucosal dissection using a live porcine model: a prospective evaluation. United European Gastroenterol J. 2018;6(9):1410-6.

16 Kato M, Gromski M, Jung Y, Chuttani R, Matthes K. The learning curve for endoscopic submucosal dissection in an established experiment setting. Surg Endosc. 2013;27(1): 154-61.

17 Percie du Sert N, Hurst V, Ahluwalia A, Alam $\mathrm{S}$, Avey MT, Baker M, et al. The ARRIVE guidelines 2.0: updated guidelines for reporting animal research. PLoS Biol. 2020;18(7): e3000410.

18 Kuttner-Magalhaes R, Dinis-Ribeiro M, Bruno MJ, Marcos-Pinto R, Rolanda C, Koch AD. Training in endoscopic mucosal resection and endoscopic submucosal dissection: face, content and expert validity of the live porcine model. United European Gastroenterol J. 2018;6(4):547-57.

19 Fujishiro M, Jung HY, Goda K, Hirasawa K, Kakushima N, Lee IL, et al. Desirable training and roles of Japanese endoscopists towards the further penetration of endoscopic submucosal dissection in Asia. Dig Endosc. 2012; 24(Suppl 1):121-3.

20 Goda K, Fujishiro M, Hirasawa K, Kakushima $\mathrm{N}$, Morita Y, Oda I, et al. How to teach and learn endoscopic submucosal dissection for upper gastrointestinal neoplasm in Japan. Dig Endosc. 2012;24(Suppl 1):136-42.

21 Lee JG, Park CH, Chung H, Park JC, Kim DH, Lee BI, et al. Current status and trend in training for endoscopic submucosal dissection: a nationwide survey in Korea. PLoS One. 2020; 15(5):e0232691.

22 van der Wiel SE, Küttner Magalhães R, Rocha Gonçalves CR, Dinis-Ribeiro M, Bruno MJ, Koch AD. Simulator training in gastrointestinal endoscopy: from basic training to advanced endoscopic procedures. Best Pract Res Clin Gastroenterol. 2016;30(3):375-87.

23 Jacques J, Legros R, Charissoux A, Mesturoux L, Couquet CY, Carrier P, et al. A local structured training program with live pigs allows performing ESD along the gastrointestinal tract with results close to those of Japanese experts. Dig Liver Dis. 2016;48(12):1457-62.

24 Daoud DC, Suter N, Durand M, Bouin M, Faulques B, von Renteln D. Comparing outcomes for endoscopic submucosal dissection between Eastern and Western countries: a systematic review and meta-analysis. World J Gastroenterol. 2018;24(23):2518-36.

25 Rahmi G, Hotayt B, Chaussade S, Lepilliez V, Giovannini M, Coumaros D, et al. Endoscopic submucosal dissection for superficial rectal tumors: prospective evaluation in France. Endoscopy. 2014;46(8):670-6.

26 Yang D, Wagh MS, Draganov PV. The status of training in new technologies in advanced endoscopy: from defining competence to credentialing and privileging. Gastrointest Endosc. 2020;92(5):1016-25.

27 Koch AD, Haringsma J, Schoon EJ, de Man RA, Kuipers EJ. Competence measurement during colonoscopy training: the use of selfassessment of performance measures. Am J Gastroenterol. 2012;107(7):971-5.

28 ASGE Standards of Practice Committee; Faulx AL, Lightdale JR, Acosta RD, Agrawal $\mathrm{D}$, Bruining $\mathrm{DH}$, et al. Guidelines for privileging, credentialing, and proctoring to perform GI endoscopy. Gastrointest Endosc. 2017; 85(2):273-81.

29 Siau K, Green JT, Hawkes ND, Broughton R, Feeney M, Dunckley $\mathrm{P}$, et al. Impact of the Joint Advisory Group on gastrointestinal endoscopy (JAG) on endoscopy services in the UK and beyond. Frontline Gastroenterol. 2019;10(2):93-106.

30 Ekkelenkamp VE, Koch AD, de Man RA, Kuipers EJ. Training and competence assessment in GI endoscopy: a systematic review. Gut. 2016;65(4):607-15.

31 Koch AD, Ekkelenkamp VE, Haringsma J, Schoon EJ, de Man RA, Kuipers EJ. Simulated colonoscopy training leads to improved performance during patient-based assessment. Gastrointest Endosc. 2015;81(3):630-6. 